\title{
Hermenéutica del sí mismo y ética. Hacia una teoría del sujeto a partir de Paul Ricoeur
}

\section{Pedro Enrique García Ruiz}

¿Quién va ahí?
-jYo!
¿Quién, yo?
Molière

A Ivette

L

a ética ocupa un lugar central en el pensamiento de Paul Ricoeur y constituye, pese a ello, uno de los aspectos más conflictivos y menos estudiados de su hermenéutica. ${ }^{1}$ Esta problemática se presenta después de un largo periodo caracterizado por la necesidad de establecer los elementos básicos de una hermenéutica de los símbolos míticos, tarea precedida por el intento de replantear el análisis intencional de la fenomenología trascendental hacia el ámbito de lo que Husserl llamó lo pre-predicativo y que será designado como tarea de una fenomenología de la voluntad; este proyecto tendrá su continuación en la elaboración de una teoría hermenéutica ya no centrada exclusivamente en los símbolos, sino también en los textos y verá su culminación en los estudios sobre el tiempo y la narración. No pretendo mostrar aquí el desarrollo de la obra de Ricoeur, únicamente señalar que la cuestión propiamente ética es tardía y se inaugura con la llamada, por él mismo, "pequeña ética” esbozada en Sí mismo como otro. Una tesis se desprende de esta caracterización: únicamente con el planteamiento de la identidad narrativa se presenta la ética como una instancia, la más importante, de la hermenéutica del sí que conforma el último estadio de la filosofía de Ricoeur. ${ }^{2}$ Este ensayo busca mostrar a qué cuestiones quiere responder

${ }^{1}$ Cf. Alain Thomasset, Paul Ricoeur. Une poetique de la morale: aux fondaments d'une éthique herméneutique et narrative dans une perspective chrétienne. Lovaina, Universidad de Lovaina, 1996; Andris Breitling, dir., Das herausgeforderte Selbst: Perspektiven auf Paul Ricoeurs Ethik. Wurzburgo, Königshausen \& Neumann, 1999; Burkhard Liebsch, dir., Hermeneutik des Selbst: im Zeichen des Anderen: zur Philosophie Paul Ricoeur. Friburgo/Múnich, Karl Alber, 1999.

${ }^{2}$ En otro lugar he intentado mostrar las implicaciones ético-políticas de esta hermenéutica, $c f$. mi artículo "Constructivismo ético y teleología del bien: Rawls y Ricoeur sobre lo justo”, en Signos Filosóficos, núm. 2. México, Plaza y Valdés/UAMIztapalapa, 1999, pp. 117-138. 
dicha hermenéutica para, posteriormente, indicar su relación con la ética. Detrás de este "giro" ético en la hermenéutica ricoeuriana se encuentra la conjunción de tres tradiciones filosóficas que permiten tal planteamiento: la fenomenología, la hermenéutica y la filosofía analítica.

En un texto titulado significativamente "De la interpretación", Ricoeur señala la tradición en la que se instala su obra. "Me gustaría caracterizar la tradición filosófica a la que pertenezco por tres rasgos: está en la línea de una filosofía reflexiva; se encuentra en la esfera de influencia de la fenomenología husserliana; quiere ser una variante hermenéutica de esta fenomenología". ${ }^{3}$ La filosofía reflexiva francesa encontró sus máximos representantes contemporáneos en Jules Lachelier y Jules Lagneau, ${ }^{4}$ pero sobre todo en Jean Nabert cuya obra define con mucho el pensamiento de Ricoeur, pues es a partir de esta tradición que nuestro autor pone como una de las tareas más importantes de la hermenéutica filosófica mostrar que el "yo" postulado por las filosofías clásicas del sujeto no expresa una tesis inconmovible, sino un problema que debe ser replanteado desde su misma raíz y la hermenéutica, en tanto que variante de la fenomenología, puede ofrecer una posible solución. ${ }^{5}$ Se trata de "la tesis de la preeminencia del sentido sobre la conciencia de sí", ${ }^{6}$ que en el fondo no hace más que expresar una convicción de Lagneau sobre la reflexión: en tanto que apropiación de nuestro esfuerzo por existir a través de las obras que dan testimonio de ello, la reflexión no permite sostener un cogito autárquico y transparente como lo pretendió en su momento Descartes, en su lugar podemos hablar, según una afortunada expresión de Ricoeur, de un cogito herido o humillado (cogito blessé) que encuentra el camino de la identidad y la comprensión de sí a través de un rodeo (détour) por lo otro: se trata de una operación de "distanciación" como crítica de las ilusiones del sujeto. "Contrariamente a la tradición del cogito y a la pretensión del sujeto de conocerse a sí mismo por una intuición inmediata, sostengo que no nos comprendemos más que por el gran rodeo de los signos de la humanidad depositados

\footnotetext{
${ }^{3}$ Paul Ricoeur, "De l'interprétation", en Du texte à l'action. Essais d'herméneutique II (1986). París, Seuil, 1998, p. 29.

${ }^{4}$ En su "mémoire de maîtrise", sostenida en 1934, Ricoeur estudió Le problème de Dieu chez Lachelier et Lagneau, y en 1994 dictó una conferencia en la Universidad de la Sorbonne titulada "Le jugement et la méthode réflexive selon Jules Lagneau", en un testimonio de fidelidad a la filosofía reflexiva. $C f$. F. Dosse, Paul Ricoeur. Les sens d'une vie. París, Éditions La Découverte, 2001, pp. 15-31.

5 Cf. F. Dastur, "De la phénoménologie trascendantale à la phénoménologie herméneutique", en J. Greisch y R. Kearney, eds., Paul Ricoeur. Les métamorphoses de la raison herméneutique. París, Les Éditions du Cerf, 1991, pp. 37-50.

${ }^{6}$ P. Ricoeur, "Phénoménologie et herméneutique: en venant de Husserl", en $D u$ texte à l'action, p. 64.
} 
en las obras de la cultura". ${ }^{7}$ La hermenéutica del sí parte de la posibilidad de establecer un discurso filosófico sobre el sí mismo que se sitúe entre la idea sustancialista del sujeto y su total negación. Se plantean así dos extremos: las filosofías del cogito y las filosofías del cogito depuesto, cuyos representantes son Descartes y Nietzsche, respectivamente. Frente a las filosofías del "yo" (Je), Ricoeur propone una hermenéutica del "sí" (Soi) como un punto medio entre estas propuestas; ya Gadamer había señalado, a este respecto, que "Ricoeur nunca adopta una postura de oposición sin ofrecer cierta forma de reconciliación". 8

La búsqueda de una estructura de la experiencia que pudiera conciliar el tiempo histórico y el relato de ficción, llevada a cabo en Tiempo y narración, condujeron hacia la identidad narrativa como el punto de inflexión entre el tiempo cosmológico, histórico y el derivado de la ficción literaria. Sí mismo como otro, busca mostrar cómo dicha identidad forma parte constitutiva de la noción de sí. Ya en Tiempo y narración se indicaba:

La identidad narrativa no equivale a una ipseidad verdadera sino gracias a este momento decisivo, que hace de la responsabilidad ética el factor supremo de la ipseidad. Lo atestiguan los análisis bien conocidos de la promesa y, para decirlo con una palabra, toda la obra de Emmanuel Levinas. Sin embargo, la defensa que la teoría de la narración podría oponer a la ambición de la ética de regir por sí sola la constitución de la subjetividad sería la de recordar que la narratividad no está desprovista de toda dimensión normativa, valorativa, prescriptiva. ${ }^{9}$

En tanto que el deseo de ser no se da con plenitud, se debe realizar una interpretación de la existencia que indique las distintas expresiones en las que ésta se manifiesta, y cuya estructura constituye la raíz de la ética. Porque la reflexión no es una intuición inmediata que pone al yo frente a sí mismo, cabe hablar de una inserción de la hermenéutica en la filosofía reflexiva. En un artículo dedicado al pensamiento de Jean Nabert, Ricoeur señala que siendo imposible sostener la tesis de una reflexión absoluta (parce que la réflexion

${ }^{7}$ P. Ricoeur, "La fonction herméneutique de la distantation", en Du texte à l'action, p. 130.

${ }^{8}$ H.-G. Gadamer, "The Hermeneutics of Suspicion", en J. N. Mohanty, ed., Phenomenology and the Human Sciences. Dordrecht, Kluwer Academic Publishers, 1985, p. 73 .

9 P. Ricoeur, Tiempo y narración. III. El tiempo narrado. México, Siglo XXI, 1996, p. 1001. 
n'est pas une intuition de soi par soi), la reflexión "puede ser, debe ser una hermenéutica". ${ }^{10} \mathrm{El}$ paso de la filosofía reflexiva a la hermenéutica está dado por una renuncia a la idea de una mediación total donde la intuición de sí coincidiría con la transparencia de un sujeto absoluto. La filosofía reflexiva ha tenido como finalidad, desde Descartes y Kant hasta Nabert, la comprensión de uno mismo como sujeto de operaciones cognoscitivas, estimativas, volitivas, valorativas, etcétera. La reflexión es un acto a través del cual el sujeto capta las operaciones en las que se dispersa y se torna una tarea primordial de la hermenéutica la búsqueda de la identidad de sí. ${ }^{11}$ El principio básico de la filosofía reflexiva lo expresó Kant en términos paradigmáticos: "El yo pienso debe poder acompañar a todas mis representaciones". Esto sugiere que el "yo" reflexivo es resultado de un esfuerzo hermenéutico, pues es evidente que si el "yo pienso" debe poder acompañar a las representaciones es porque hay momentos de conciencia sin yo; recobrar esta identidad es la finalidad de la mediación reflexiva. ${ }^{12}$

El proyecto de una fundamentación última, asociada al principio de la autoconciencia como fuente de sentido y validez, encuentra su límite en la determinación hermenéutica de la existencia que Ricoeur asume de Heidegger, pero ante de todo de Dilthey, pues la búsqueda de la identidad de sí que exige la filosofía reflexiva se realiza a través del rodeo que efectúa el sujeto por lo otro teniendo como efecto el extrañamiento de sí mismo (Verfremdung). La mediación de las obras, los actos, los símbolos, los signos, los textos, etcétera, conforma la estructura de esta exteriorización (Äusserung) desde la cual el sujeto da testimonio de sí. Este proceso se encuentra esbozado en la recuperación de Dilthey del llamado por Hegel "espíritu objetivo", pero sin su carga idealista, esto es, sin apelar a una dialéctica del espíritu absoluto; la mediación por lo otro de sí es la expresión (Ausdruck) de la vida. ${ }^{13}$ Aquí ya se encuentra configurada la vía larga (voie longue) de la hermenéutica en oposición a la vía corta (voie courte) de la ontología de la comprensión desarrollada por Heidegger; para éste la relación sujeto-objeto no es primaria, pues corresponde a una consideración exclusivamente epistemo-

${ }^{10} \mathrm{P}$. Ricoeur, "L'acte et le signe selon Jean Nabert", en Le conflit des interprétations. París, Seuil, 1969, p. 221.

${ }^{11}$ Cf. P. Ricoeur, "De l'interprétation", en op. cit., p. 29.

${ }^{12}$ Cf. P. Ricoeur, Philosophie de la volonté. I. Le volontaire et l'involontaire (1950). París, Aubier, 1988, pp. 58-59. Cf. Jean Paul Sartre, La trascendencia del ego. Buenos Aires, Calden, 1968, p. 13.

${ }^{13}$ Cf. P. Corset, "Wilhelm Dilthey (1833-1911). Le pacte moderne entre épistémologie et herméneutique", en vV. AA., Comprendre et interpréter. Le paradigme herméneutique de la raison. París, Institut Catholique de París, Beauchesne, 1993, pp. 127-149. 
lógica de la vida humana; el conocimiento (Erkennen) es un "modo de ser" derivado de una estructura más fundamental: el "comprender" (Verstehen). ${ }^{14}$

El problema del comprender en Ser y tiempo se aleja del marco psicológico en que lo había situado Dilthey en tanto que método propio de las ciencias del espíritu. La empatía (Einfühlung), definida como la comprensión de las vivencias psíquicas del otro, fue ampliamente tratada en la literatura fenomenológica y de la Lebensphilosophie de entonces (Th. Lipps, E. Becher, E. Spranger, E. Stein, etcétera), ${ }^{15}$ pero fueron Dilthey y Max Scheler quienes más contribuyeron a su difusión como un problema filosófico de primer orden y que Husserl retomará posteriormente bajo la denominación de la "experiencia de lo extraño" (Fremderfahrung). Scheler indicó un conjunto de problemas en torno a la comprensión que no han sido tomados en cuenta y que una fenomenología renovada deberá apropiarse, pues la crítica de la comprensión que realiza Heidegger en Ser y tiempo va dirigida precisamente a ese ámbito que Scheler señaló como último referente de la comprensión: la ética. ${ }^{16}$ Si la comprensión estaba ligada, al menos desde Dilthey y Lipps, a la comprensión del otro, con Heidegger se realiza un desplazamiento hacia una problemática estrictamente ontológica en la cual la comprensión del psiquismo ajeno es eliminada como un falso problema, pues la comprensión es para Heidegger un tema propio de una hermenéutica del "ser en el mundo" y no del "ser con otro". Ricoeur lo ha indicado claramente: "La pregunta por el mundo toma el lugar de la pregunta por el otro. Al mundanizar así el comprender, Heidegger lo despsicologiza" ${ }^{17}$

La oposición, ya clásica desde la hermenéutica romántica, entre "comprender" (Verstehen) y "explicar" (Auslegen), puede ser superada a través de

${ }^{14}$ Karl O. Apel, "Das Verstehen. Eine Problemgeschichte als Begriffgeschichte", en Archiv für Begriffgeschichte, 1, 1955, pp. 142-199.

${ }^{15}$ Ibid., pp. 150 y ss. Para Apel sólo en Alemania el concepto de "comprensión" ha adquirido un sentido estrictamente filosófico; Ricoeur, en un artículo publicado en 1989, trata de mostrar que "la théorie de l'interprétation n'a pas connu en France l'essor dont elle a bénéficié en Allemagne" y que "une théorie general de l'interprétation fondée sur une théorie philosophique de la comprensión fait presque entièrement défaut en langue française" (P. Ricoeur, "Interprétation", en Lectures 2. La contrée des philosophes. París, Seuil, 1999, pp. 456-457).

${ }^{16}$ Cf. M. Scheler, Esencia y formas de la simpatía. Buenos Aires, Losada, 1957, p. 300.

${ }^{17}$ P. Ricoeur, "La tâche de l'herméneutique: en venant de Scheliermacher et de Dilthey", en Du texte à l'action, p. 100. En este punto tampoco Husserl pudo, según Ricoeur, dar cuenta de la alteridad del otro. "La méthode interprétée [de Husserl] tend vers un idéalisme solipsiste qui déleste définitivament la 'chose' de son alterité relative et qui ne réussit pas à rendre compte de l'alterité absolue d'autrui, de la seconde personne" (P. Ricoeur, "Sur la phénoménologie", en À l'école de la phénoménologie. París, Vrin, 1986, p. 147). 
una concepción amplia de la interpretación (Deutung) donde la pregunta por la alteridad no quede eliminada por una ontologización del comprender establecida por Heidegger y continuada por Gadamer. ${ }^{18}$ La interpretación constituye la disciplina que abarca la explicación estructural y la comprensión existencial; la triangulación explicar-comprender-interpretar permite proponer una concepción de la hermenéutica más atenta a los aportes de las ciencias humanas como lo son la teoría de la acción, la teoría de los textos y la teoría de la historia, en cuyo ámbito la dialéctica entre explicar y comprender se muestra más fructífera que la oposición establecida por la hermenéutica alemana. Esto conforma la "vía larga" de la comprensión de sí; pero más que oponerse a la "vía corta" operada por Heidegger y Gadamer al colocar la "pertenencia” en el centro de su propuesta, Ricoeur trata de completar esta hermenéutica ontológica con el concepto del distanciamiento que se opera frente al mundo asumido como un texto.

Desde que se la somete a la Selbstdarstellung -a la presentación de sí- de la cosa del texto, una crítica de las ilusiones del sujeto parece incluida en el acto mismo de comprenderse delante del texto. Precisamente porque el sujeto se lleva a sí mismo en el texto y porque la estructura de comprensión de la cual habla Heidegger no podría ser eliminada de la comprensión que quiere dejar hablar al texto, la crítica de sí forma parte integrante de la autocomprensión delante del texto. ${ }^{19}$

La filosofía de la reflexión puede ser contraria a la filosofía de la conciencia ${ }^{20}$ la experiencia originaria del despojamiento de sí que suprime la reflexión a través de la reflexión misma, no implica la ruina del sujeto. Ricoeur sostendrá que toda hermenéutica es explícita o implícitamente comprensión de sí por el desvío de la comprensión del otro. ${ }^{21}$ La identidad narrativa puede responder a la exigencia de una hermenéutica que busca, a través de la fenomenología, una identidad no sustancial. Dar cuenta de este cogito herido conservando la herencia de la filosofía reflexiva sin volver a los supuestos de las filosofías de la conciencia es lo que se propondrá una "fenomenología hermenéutica de la persona" o del sí mismo.

${ }^{18} C f$. P. Ricoeur, "La foction herméneutique de la distanciation", en Du texte à l'action, pp. 113-131

${ }^{19}$ P. Ricoeur, "Herméneutique philosophique et herméneutique biblique", en $\mathrm{Du}$ texte à l'action, pp. 146-147.

${ }^{20}$ P. Ricoeur, "Existence et herméneutique", en Le conflit des interprétations, p. 21.

${ }^{21}$ Ibid., p. 20. 
En relación con "conciencia", "sujeto", "yo", la persona aparece como un concepto superviviente y resucitado. ¿Conciencia?, ¿cómo creer todavía en la ilusión de transparencia que se relaciona con este término, después de Freud y el psicoanálisis? ¿Sujeto?, ¿cómo mantener todavía la ilusión de fundamentación última en algún sujeto trascendental después de la Escuela de Frankfurt? ¿El yo?, ¿quién es impasible ante la impotencia del pensamiento para salir del solipsismo, a menos que no se parta, como lo hace Emmanuel Levinas, del rostro del otro, eventualmente de una ética sin ontología? He aquí por qué prefiero decir persona que conciencia, sujeto, yo. ${ }^{22}$

El despojamiento del sujeto que realiza la hermenéutica muestra la urgencia de establecer criterios desde los cuales se pueda llegar a una comprensión de sí pero sin recurrir a la tesis de una intuición inmediata. La recuperación de esta problemática en el marco más amplio de un análisis del tiempo y la narración ya sugiere la polémica de fondo que motiva la elaboración de la hermenéutica del sí: una respuesta a la vía corta de la comprensión sostenida por Heidegger en Ser y tiempo. Esta crítica encuentra una de sus primeras exposiciones en dos artículos editados en Le conflit des interprétations, ${ }^{23}$ ahí se propone una concepción de la subjetividad que ofrece las bases conceptuales para establecer un puente con los temas que la filosofía analítica ha desarrollado bajo la denominación de "teoría de la acción" e "identidad personal", siendo la primera un paso previo a los temas propiamente éticos, pues a pesar de que es tentativo identificar sin más la teoría de la acción con la ética, Ricoeur tiene el cuidado metodológico de indicar la naturaleza propia de la red conceptual de la acción que es previa al planteamiento ético, pues este es prescriptivo y normativo mientras que aquél es analítico-descriptivo. ${ }^{24} \mathrm{La}$ recuperación de la ética vendrá seguida de la problemática de la identidad narrativa que se presenta al final del tercer tomo de Tiempo y narración y que en Sí mismo como otro permite establecer un intenso diálogo con las tesis centrales de la filosofía analítica sobre la identidad personal. La incursión de Ricoeur en esta tendencia filosófica se debe a su convicción de que la fenomenología hermenéutica no tiene los elementos conceptuales para solu-

${ }^{22}$ P. Ricoeur, "Muert le personalisme, revient la personne...", en Lectures 2. La contrée des philosophes, p. 198.

${ }^{23}$ P. Ricoeur, "Heidegger et la question du sujet", y "La question du sujet: le défi de la sémiologie", en Le conflit des interprétations, pp. 222-232 y 233-262, respectivamente.

24 P. Ricoeur, El discurso de la acción. Madrid, Cátedra, 1988, p. 26. Cf. R. Kearney, ed., Paul Ricoeur: The Hermeneutics of Action. Londres, Sage Publications, 1996. 
cionar los obstáculos teóricos a los que se enfrenta una filosofía que pretende dar cuenta de la cuestión de la subjetividad apelando exclusivamente a la tradición reflexiva. Ricoeur desea establecer "una confrontación constructiva" ${ }^{25}$ que permita "una nueva alianza entre la tradición analítica y la tradición fenomenológica y hermenéutica". ${ }^{26}$

La incorporación de la filosofía analítica al proyecto de una hermenéutica del sí mismo no es el resultado de "la ambición maniática de lograr un matrimonio forzoso entre dos familias de espíritu que se han tratado poco". ${ }^{27} \mathrm{La}$ hermenéutica del sí mismo, gracias a este momento analítico-descriptivo, puede "mantenerse a igual distancia del cogito exaltado por Descartes que del cogito despojado de Nietzsche". ${ }^{28}$ El problema de la identidad personal, que en el ámbito de la filosofía analítica encontró a sus máximos representantes en Derek Parfit, Sydney Shoemaker y David Wiggins, ha llevado en muchos casos a espeluznantes trivialidades en torno a la subjetividad y el conocimiento de sí a través de la elucubración de situaciones fantásticas e inverosímiles (transplantes de cerebro parciales y totales, teletransportaciones, duplicaciones de mente y cuerpo, etcétera). ${ }^{29}$ Las paradojas surgidas de este tipo de planteamientos orilló a algunos de estos autores, especialmente a Derek Parfit, a rechazar la identidad como un problema relevante para la vida humana. ${ }^{30} \mathrm{Y}$ es precisamente esta postura la que lleva a Ricoeur a dejar el ámbito de los estudios de la filosofía analítica sobre la subjetividad para retomar la hermenéutica y, concretamente, la teoría de la identidad narrativa como punto de inflexión entre el punto de vista puramente descriptivo del análisis lingüístico y el prescriptivo ya involucrado en la narración. Peter Kemp sostiene la tesis de una ética narrativa ${ }^{31}$ y en efecto: a pesar de que la problemática de la identidad narrativa únicamente aparece en el tercer tomo de Tiempo y narración, su lugar en la obra de Ricoeur es central, pues en ella se sintetizan los estudios

${ }^{25}$ P. Ricoeur, Sí mismo como otro. Madrid, Siglo XXI, 1996, p. XXX.

${ }^{26}$ Ibid., p. 106. Respecto a la "alianza" entre fenomenología hermenéutica y filosofía analítica en la obra de Ricoeur $c f$. H. Ineichen, Philosophische Hermeneutik. Friburgo/Múnich, Karl Alber, 1991.

${ }^{27}$ Ibid., p. XXIX.

${ }^{28}$ Ibid., p. XXXVII.

${ }^{29} C f$. D. Ihde, "Literary and Science Fictions. Philosophers and Technomyths", en R. A. Cohen y J. I. Marsh, eds., Ricoeur as Another. The Ethics of Subjectivity. Nueva York, Universidad Estatal de Nueva York, 2002, pp. 93-105.

${ }^{30}$ D. Parfit, Reason and Persons. Oxford, Universidad de Oxford, 1986, pp. 255 y ss. $C f$. P. Engel, "Las paradojas de la identidad personal", en L. Olivé y F. Salmerón, eds., Identidad personal y colectiva. México, UNAM, Instituto de Investigaciones Filosóficas, 1994, pp. 37-64.

${ }^{31}$ P. Kemp, "Ethics and Narrativity", en L. E. Hahn, ed., The Philosophy of Paul Ricoeur. Chicago/La Salle, Open Court, 1995, pp. 371-394. 
anteriores dedicados a la teoría de la acción en la filosofía analítica, cuya confrontación con la fenomenología hermenéutica lo habían llevado, como en el caso de Elizabeth Anscombe y Anthony Kenny, a una recuperación de la teoría aristotélica del actuar. "Aristóteles es a la vez el padre del método fenomenológico y del análisis lingüístico aplicado al actuar”. ${ }^{32}$ La red conceptual de la acción, recuperada en Sí mismo como otro bajo la denominación de una dialéctica entre descripción, narración y prescripción, es requerida en el punto en que el planteamiento de la filosofía analítica en torno a la intención, el actuar y la identidad personal llegan a su límite: el papel aparentemente irrelevante que juega el cuerpo y lo vivido, pues como lo muestra, por ejemplo, la obra de Parfit a través de los llamados puzzling cases, la subjetividad es concebida de tal manera que no cabe la distinción propuesta por Ricoeur entre una identidad ipse y una identidad idem, quedando finalmente reducida al cerebro, mientras que la corporalidad y la atribución narrativa no son considerados como elementos constitutivos de la formación de la identidad. ${ }^{33}$

Frente a una postura que busca renunciar a cualquier criterio de identidad - "Mi tesis es que podríamos describir nuestras vidas de modo impersonal" afirma paradójicamente Parfit-,${ }^{34}$ Ricoeur sostiene que la pura descripción no basta y tiene que ser introducido el nivel prescriptivo que con el narrativo conforman el núcleo de la hermenéutica del sí: la unidad analógica del actuar humano. Entre la designación del sujeto hablante, el obrar del agente de la acción o la imputación moral de la acción, no hay una oposición, sino una unidad analógica que otorga sentido a una ontología del actuar humano. La identidad narrativa posibilita la interrogación que Ricoeur establece como guía de su hermenéutica del sí: ¿quién?, es decir, ¿quién habla?, ¿quién actúa?, ¿quién es moralmente responsable? La noción de identidad narrativa permite asignar a un individuo o a una comunidad una determinada identidad comprendida como una categoría práctica. "Decir la identidad de un individuo o de una comunidad es responder a la pregunta: ¿quién ha hecho esta acción?, ¿quién es su agente, su autor? [...] Responder a la pregunta ‘¿quién?’, como lo había dicho con toda energía Hannah Arendt, es contar la historia de una vida". ${ }^{35}$ De manera que el conocimiento de sí es, según la expresión que Ricoeur toma de la Apología de Sócrates, el fruto de una vida examinada. "En lugar del yo atrapado por sí mismo, nace un sí mismo instruido por los símbolos cultu-

${ }^{32}$ P. Ricoeur, El discurso de la acción, p. 136.

${ }^{33} C f$. H. J. Adriaanse, "La mienneté et le moment de la dépossesion de soi. Le débat de Ricoeur avec Derek Parfit”, en VV. AA., Paul Ricoeur. L'herméneutique à l'école de la phénoménologie. París, Institut Catholique de París, Beauchesne, 1995, pp. 3-19.

${ }^{34}$ D. Parfit, op. cit., p. 217. Las cursivas son mías.

${ }^{35}$ P. Ricoeur, Tiempo y narración III, p. 997. 
rales, en cuya primera fila están los relatos recibidos en la tradición literaria. Son ellos quienes nos confieren una unidad no sustancial sino narrativa". ${ }^{36}$

Esta "fenomenología hermenéutica de la persona" ${ }^{37}$ se encuentra estructurada en cuatro capas (couches) o estratos (strates): lenguaje, acción, narración y vida ética, cuyo suelo común es proporcionado por la analogía del actuar (agir) humano expresado en la dialéctica entre describir, narrar y prescribir. El concepto ricoeuriano de ethos se instala en la tradición de la filosofía práctica aristotélica, en concreto, en la idea de vida buena o de vida verdadera. ${ }^{38}$ A este concepto de ética, que opera de manera implícita en Tiempo $y$ narración, se opone el de "moral" designando con él la normatividad de carácter universal propia de las éticas formales de cuño kantiano. La recuperación de la filosofía práctica aristotélica frente a las éticas formales, así como la centralidad que juegan las nociones de "unidad narrativa de una vida" y la de "tradición", permite definir la identidad como un concepto hermenéutico que abarca las distintas prácticas, creencias, etcétera, que ofrecen unidad y sentido a la vida tanto de un individuo como de una comunidad. ${ }^{39}$ "Si mi vida no puede ser aprehendida como una totalidad singular no podré nunca desear que sea una vida lograda, realizada". ${ }^{40}$ La identidad narrativa permite mediar entre la descripción y la prescripción, pues plantea la cohesión de una persona a lo largo de acontecimientos que, en su conjunto, conforman la que llamamos una vida, sin caer en las paradojas en torno a la identidad personal de la filosofía analítica.

En este recorrido narrativo la identidad del ipse no se reduce a la identidad sustancial del idem, en el sentido de lo cambiante, sino que se conjuga con una mutabilidad fundamental. La función mediadora del relato consiste en sostener unidos la mutabilidad anecdótica de una vida con la configuración de una historia. ${ }^{41}$

La intencionalidad ética es definida como el "deseo de una vida realizada -con y para otros- en instituciones justas". ${ }^{42}$ En esta formulación se presenta

${ }^{36}$ P. Ricoeur, "La vida: un relato en busca de narrador", en Educación y política. De la historia personal a la comunión de libertades. Buenos Aires, Docencia, 1984, p. 58.

${ }^{37}$ P. Ricoeur, "Approches de la personne", en Lectures 2. La contrée des philosophes, p. 204.

38 Aristóteles, Ética nicomáquea. México, UNAM, 1983, I, 8, 1098b.

${ }^{39}$ Cf. A. MacIntyre, Tras la virtud. Barcelona, Crítica, 1987, pp. 252 y ss.

${ }^{40}$ P. Ricoeur, Sí mismo como otro, p. 160.

${ }^{41}$ P. Ricoeur, "Individuo e identidad personal", en vv. AA., Sobre el individuo. Barcelona, Paidós, 1990, p. 86.

${ }^{42}$ P. Ricoeur, Sí mismo como otro, p. 204. 
la articulación entre la identidad narrativa, cuya expresión ética es la estima de sí, y la problemática de la alteridad: la relación con los demás por mediación de las instituciones. O en otros términos: la ética como preocupación de sí, preocupación del otro, y preocupación de la institución; se establece así una correlación entre estas tres instancias: elemento reflexivo, elemento de alteridad y elemento institucional. ${ }^{43}$ La tesis de la filosofía reflexiva en torno a la raíz de la ética, a saber, llevar a su plenitud nuestra existencia, encuentra un lugar situado antes de lo normativo y lo formal, es decir, el deseo de realizar una vida plena es la expresión originaria de la persona cuya búsqueda de la felicidad es anterior a la obligatoriedad que impone la norma moral como ley y justicia. ${ }^{44}$ Hay sujeto responsable en la medida en que éste es capaz de estimarse a sí y, por ende, obrar intencionalmente por lo que la estima de sí es el momento reflexivo del actuar.

De esta manera, la hermenéutica del sí intenta situarse en una vía distinta a la, aparentemente, inevitable alternativa que plantea la fenomenología y la hermenéutica actual: Heidegger o Levinas.

En la coyuntura de la filosofía contemporánea, marcada por la alternativa Heidegger/Levinas, la tentativa aquí propuesta sería la de escapar a una ontología distinta a la que Levinas rechaza, pero también distinta a la que Heidegger desarrolla, en este sentido hay que decir: ni Heidegger ni Levinas. ${ }^{45}$

Tanto la ontología heideggeriana como la ética levinasiana coinciden finalmente en un punto: tratan de acceder a la problemática de la subjetividad sin mediación alguna y la ontología que busca elaborar Ricoeur se deriva de su lectura crítica de estos autores. Frente a Heidegger, se propone la vía larga de la comprensión como relación de un sí mismo con lo otro que, ahora ante la otredad hiperbólica de Levinas (al menos el "Levinas" de Ricoeur), sale al encuentro en el horizonte de la intencionalidad ética, de manera que la alteridad forma parte originariamente de la identidad del sí, ${ }^{46}$ de ahí la estrecha relación

${ }^{43} C f$. E. Ganty, "Du sujet du droit au sujet de droit: attestation et reconnaissance", en F.-X. Druet y E. Ganty, eds., Rendre justice au droit: en lisant "Le juste" de Paul Ricoeur. Namur, Presses Universitaires de Namur, 1999, pp. 37-49.

${ }^{44} C f$. P. Ricoeur, "Ethique et morale: visée téléologique et perspective déontologique", en Ragione pratica, Libertà, Normatività. Roma, Pontificia Università Lateranense/Herder, 1991, pp. 353-366.

${ }^{4}$ P. Ricoeur, "L'attestation: entre phénoménologie et ontologie", en J. Greisch y R. Kearney, eds., Paul Ricoeur. Les métamorphoses de la raison herméneutique, p. 381 .

${ }^{46} C f$. F. Dastur, "Das Gewissen als innerste Form der Andersheit. Das Selbst und 
que se establece entre estima de sí y solicitud, pues "no pueden vivirse y pensarse la una sin la otra" ${ }^{47}$ La identidad no se define ya como un acto puro de reflexión, sino como un testimonio de sí a través de las obras y las acciones. ${ }^{48}$ "Como Charles Taylor lo señala en sus Philosophical Papers, el hombre es un animal que se interpreta a sí mismo. Mas esta autointerpretación no es simple, ni directa; ella adopta el camino sinuoso de la apreciación ética de nuestras acciones". ${ }^{49}$ Esta estima de sí lleva a la fenomenología hermenéutica de la persona hacia la ontología que la sustenta. ¿Qué ontología es la que supone dicha hermenéutica? Ricoeur indica en el séptimo estudio de Sí mismo como otro: "En el plano ético, la interpretación de sí se convierte en estima de sí. Como ésta, la estima da lugar a la controversia, a la contestación, a la rivalidad, en una palabra, al conflicto de las interpretaciones, en el ejercicio del juicio práctico" ${ }^{50}$ Este conflicto de las interpretaciones tiene como trasfondo los distintos proyectos de vida buena y como modelo reflexivo la phrónesis, pero hay que tener en cuenta que para Ricoeur, igual que para Heidegger, la filosofía práctica de Aristóteles contiene una ontología más que una ética, ${ }^{51}$ de modo que las distintas expresiones que conforman el universo conceptual de la ética aristotélica pueden ser reintroducidas en el marco de una ontología en la que la vida humana se define como un actuar (praxis), ${ }^{52}$ y concretamente como una unidad analógica de este actuar humano.

La atestación de sí, desde el punto de vista de la fenomenología y la filosofía analítica, nos permite distinguir dos modos de identidad: ipse e idem, pero ahora podemos ver en ellos no sólo una distinción entre una constelación de significados y otra, sino entre dos modos de ser, de ahí que se hable del "compromiso ontológico de la atestación”. Esta ontología, que llamaré analógica ¿escapa a la vía directa de la comprensión de sí propuesta por Heidegger y a

der Andere bei Paul Ricoeur", en B. Waldenfels e I. Därmann, eds., Der Anspruch des Anderen. Perspektiven phänomenologischer Ethik. Múnich, Wilhelm Fink, 1998, pp. 51-63.

${ }^{47}$ P. Ricoeur, Sí mismo como otro, p. 186.

${ }^{48} \mathrm{Cf}$. P. Ricoeur, "Emmanuel Levinas, penseur du témoignage", en J. C. Aeschlimann, ed., Repondré d'autrui. Emmanuel Levinas. Nauchâtel, Éditions Baconière, 1989, pp. 17-40.

${ }^{49}$ P. Ricoeur, "L'attestation: entre phénoménologie et ontologie", en op. cit., p. 394.

${ }^{50}$ P. Ricoeur, Sí mismo como otro, p. 185.

${ }^{51}$ Ibid., pp. 334-351. Cf. mi artículo "Filosofía y hermenéutica en las interpretaciones fenomenológicas de Aristóteles del joven Heidegger", en Analogía Filosófica, 15, núm. 2, 2001, pp. 101-119.

${ }^{52} C f$. F. Volpi, "Dasein comme praxis: l'assimilation et la radicalisation heideggeriene de la philosophie pratique d'Aristote", en VV. AA., Heidegger et l'idee de la phénoménologie. Dordrecht, Kluwer Academic Publishers, 1988, pp. 67-80. 
la crítica radical a toda ontología llevada a cabo por Levinas? ${ }^{23}$ La cuestión a la que apunta la hermenéutica del sí a través de sus implicaciones éticas es la manera de ser en que la subjetividad puede definirse después de las críticas al cogito. Como lo ha señalado con gran énfasis Jean Greisch, se trata de situar este cogito hermenéutico en el actual horizonte posmetafísico. ${ }^{54}$ ¿Puede la hermenéutica del sí volver a la tesis de una ontología después de la "consumación de la metafísica"? Para Ricoeur esta tarea no es únicamente posible sino también necesaria, pues la crítica de la metafísica llevada a cabo por Heidegger y sus epígonos es una crítica unilateral que, bajo la tesis de la "metafísica de la subjetividad", pretende despachar toda la riqueza conceptual que encierran las distintas filosofías del sujeto. ${ }^{55} \mathrm{Si}$ aceptamos el análisis heideggeriano con sus lapidarios resultados, no podría llevarse a cabo el intento de reactivar una posible ontología -ontología analógica- que dé cuenta de los distintos modos de ser del actuar humano.

Una ontología sigue siendo posible en nuestros días, en la medida en que las filosofias del pasado sigan estando abiertas a nuevas interpretaciones y apropiaciones, gracias a un potencial de sentido no utilizado, incluso reprimido, por el proceso mismo de sistematización y de escolarización al que debemos los grandes cuerpos doctrinales que, de ordinario, identificamos con sus creadores: Platón, Aristóteles, Descartes, Spinoza, Leibniz, etcétera. A decir verdad, si no se pudiese reavivar, liberar estos recursos que los grandes sistemas del pasado tienden a asfixiar y a enmascarar, no sería posible ninguna innovación, y el pensamiento de hoy sólo podría elegir entre la repetición y la errancia. ${ }^{56}$

En lo que toca a las implicaciones éticas de la hermenéutica del sí, hay que situarse fuera de la alternativa que plantean Heidegger y Levinas: una ontología sin ética o una ética sin ontología. La subjetividad, su estatuto ético, ¿cómo

${ }^{53} \mathrm{Cf}$. P. Ricoeur, Sí mismo como otro, pp. 330-334.

${ }^{4} \mathrm{Cf}$. J. Greisch, Le cogito herméneutique. L’herméneutique philosophique et l'héritage cartésien. París, J. Vrin, 2000, pp. 51 y ss.

55 "La nécessité intérieure qui, quant à moi, m'a guidé, ce sont plusieurs choses -et c'est à vous de voir si ça ressemble ou non à ce que font les autres, moi je ne suis pas bon juge. La première, c'est le caractère inépuisable des philosophies du passé. Sur ce terrain, je me sens vraiment très étranger au thème introduit par Heidegger parlant de la fin de la métaphysique" ("De la volonté à l'acte. Un entretien de Paul Ricoeur avec Carlos Oliveira", en Ch. Bouchindhomme y R. Rochlitz, eds., "Temps et réctit" de Paul Ricoeur en débat. París, Les Éditions du Cerf, 1990, p. 22). Cf. P. Ricoeur, "L'attestation: entre phénoménologie et ontologie", en op. cit., p. 398.

56 P. Ricoeur, Sí mismo como otro, p. 330. 
se define? El sentido de lo humano que radica en el pronombre personal "yo" se constituye por una dialéctica entre los grandes géneros de la alteridad y la identidad, de lo propio y lo ajeno, o en términos de Levinas, de lo Mismo y lo Otro. ${ }^{57}$ ¿Cómo pensar al sujeto hoy ante la crítica del psicoanálisis, la genealogía y la ideología?58 "Falta por saber si la hermenéutica de la sospecha se ha convertido en nuestra cultura moderna en el camino obligado de la búsqueda de la identidad personal" ${ }^{59}$ Sin embargo, si para Levinas esta identidad, entendida como un preservarse en el ser según el dictum de Spinoza: conatus esse conservandi est ipsa rei essentia ${ }^{60}$ no es lo que constituye a la subjetividad, ise puede conciliar su postura con la de Ricoeur, a pesar de la importancia que juega en la hermenéutica del sí y, en concreto, en la ética ricoeuriana, el concepto de conatus asociado a la dimensión primigenia de la ética como "deseo de ser"? Pues la exigencia de una comprensión mediata de sí es la tarea de la ética, y "la ética, en este sentido radical, consiste en la apropiación progresiva de nuestro esfuerzo por ser" ${ }^{61} \mathrm{El}$ conatus de Spinoza es el "enlace entre una fenomenología del sí que actúa y sufre, y el fondo afectivo y poderoso sobre el que se destaca la ipseidad". ${ }^{62}$

Para Levinas la subjetividad se estructura como un "yo", sin el cual no tendría sentido la idea misma de alteridad ${ }^{63}$ pero es un "yo" descentrado, pasivo y traumatizado por el otro. ¿Qué papel juega la dimensión reflexiva que atribuye Ricoeur a la subjetividad frente a la concepción que nos plantea Levinas? La unicidad de la subjetividad expresada en el pronombre "yo" señala el acontecimiento de la ética:

${ }^{57}$ Para un análisis de estas categorías $c f$. B. Waldenfels, "Fremderfahrung und Fremdanspruch", en Topografie des Fremden. Studien zur Phänomenologie des Fremden 1. Fráncfort del Meno, Suhrkamp, 1997, pp. 16-53.

${ }^{58} C f$. E. Guibert-Sledziewski y J.-L. Viellard-Baron, dirs., Penser le sujet aujourd'hui. París, Méridiens Klincksieck, 1988, obra en la que predomina el punto de vista del desconstructivismo y el psicoanálisis.

${ }^{59}$ P. Ricoeur, "La identidad narrativa", en Historia y narratividad. Barcelona, ICE, UAB, 1999, p. 229.

${ }^{60}$ B. de Spinoza, Éthique. Démontrée suivant l'ordre géométrique et divisée en cinq parties. Texto latín-francés. París, Granier Frères, 1929, cuarta parte, proposición XXII, p. 47.

${ }^{61}$ P. Ricoeur, "Religion, athéisme, foi", en Le conflit des interprétations, p. 442. "Le propre de la reflexión ainsi comprise, c'est de toujours considérer l'esprit dans ses actes et dans ses productions, pour s'en approprier la signification, et, d'abord, essentiellement, dans l'acte initial par lequel le sujet s'assure de soi, de son pouvoir, de sa verité" (J. Nabert, "La philosophie reflexive", apud P. Ricoeur, "Préface à Éléments pour une éthique", en Lectures 2. La contrée des philosophes, p. 228).

${ }^{62}$ P. Ricoeur, Sí mismo como otro, p. 349.

${ }^{63}$ Cf. E. Levinas, Totalidad e infinito. Ensayo sobre la exterioridad. Salamanca, Sígueme, 1987 , p. 63. 
La responsabilidad hacia el otro es la conciencia de que nadie puede sustituirme; es una conciencia de la elección del yo que es, precisamente, la constitución del yo en tanto que elegido. Así se percibe la gran importancia de lo que es necesario oponer a la ontología pura. Aquí, la ética, la prioridad de la responsabilidad, es el acto constitutivo de la unicidad misma del yo. ${ }^{64}$

Levinas realiza una destrucción del "sujeto" a partir de una crítica a los supuestos ontológicos que la tradición de la filosofía reflexiva sigue compartiendo con las filosofías clásicas de la conciencia; en este punto la obra de Ricoeur ofrece una posible mediación entre la desaparición del sujeto y su posible replanteamiento: ser yo no es necesariamente ser una identidad sustancial como conatus ni tampoco una referencia vacía como pretende la filosofía analítica. "Yo es otro". ${ }^{65}$ ¿Podría expresar esta frase de Rimbaud la idea de una subjetividad que no es transparente pero que, pese a ello, se constituye a partir de su relación con lo otro de sí? No obstante, para Levinas esta caracterización de la subjetividad está aún atada a la concepción de un yo que incluso en sus alteraciones sigue siendo idéntico, es "el primado de lo mismo o el narcisismo", ${ }^{66}$ pues el "Yo, pese a Rimbaud, no es otro" ${ }^{67}$ Proponer una teoría del sujeto implica aceptar este reto de la hermenéutica de la sospecha y tanto en la obra de Levinas como la de Ricoeur se encuentran los elementos mínimos para pensar el sujeto de otro modo. En este espacio aparentemente contradictorio entre una subjetividad despojada de todo rendimiento ontológico y una subjetividad que busca su identidad a través de lo otro y los otros, se sitúa la unicidad humana del pronombre yo: la ética.

${ }^{64}$ E. Levinas, "La ética", en J. Casado y P. Aguídez, comps., El sujeto europeo. Madrid, Pablo Iglesias, 1990, p. 12.

${ }^{65}$ P. Ricoeur, "La identidad narrativa", en op. cit., p. 228.

${ }^{66}$ E. Levinas, "La philosophie et l'idée de l'infini", en Découvrant l'existence avec Husserl et Heidegger. París, J. Vrin, 1982, p. 167.

67 "Je qui, malgré Rimbaud, n'est pas un autre" (E. Levinas, Hors sujet. París, Le Livre de Poche, 1997, p. 212. 